\title{
LOS DERECHOS HUMANOS EN LA HISTORLA DE LAS CONSTITUCIONES DEL PERÚ
}

\section{Nicolás de Piérola y Balta †}

Quien fuera doctor en derecbo, abogado, profesor de Derecbo Internacional Priblico de la Facultad de Derecbo y Ciencias Poiñicas de la Linsuersidad de Lima. Miembro titular de la Sociedad Paruana de Derecbo Internacional y miembro del Comile de Naciones Linidas para la Eliminación de la Discriminación Ractal.

$\mathrm{L}$ a moderna doctrina de los derechios humanos se inicia en Europa y los Estados Unidos en la segunda mitad del sigio XVIII, y evoluciona, hasta alcanzar vigencia en todo el mundo, con el establecimiento de la Organización de las Naciones Unidas y la Declaración Universal de los Derechos Humanos.

Fista evolución se manifiesta también en nuestro derecho interno. Desde la Constitución de 1812, aprobada por las Cortes de Cadiz, hasta la actual, promulgada por la Asamblea Constinyente de 1979, se va recogiendo las nuevas ideas $y$ aportaciones de la doctrina de los derechos humanos. Significa esto que, desde inicios del sigjo pasado, ha estado vigente el principio de que el Estado debe promover el bien común y que, al mismo tiempo, todos los seres humancos tenemos ciertos derechos inalienables como son el derecho a la vida y las libertades fundamentales, que el Estado debe cautelar y respetar.

A la luz de estas consideraciones, examinemos cacta una de las constituciones que han tenido vigencia en el Perü.

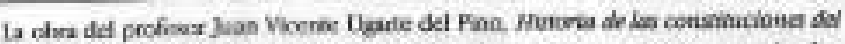

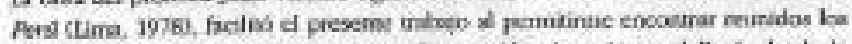

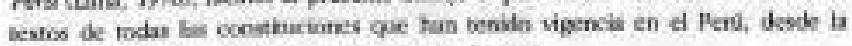
Canatbucisin de Cactic, hasta b Consinuckes de 1935 


\section{CONSTrTuCión POLfTICA DE LA MONARQUUA ESPANOLA}

Fue aprobada por las Cortes de Cadiz y promulgada el 19 de marzo de 1812 . Tuvo breve vigencia, pues fue derogada en 1814 por el rey Fernando VII, al volver a Esporâa después de su exilio en Francia.

Hemos considerado pertinente incluir el estudio de la Constitución de Cádiz, por tres razones: en primer lugar, pocque tuvo vigencia en el Perí al establecerlo así la propia Constitución, cuyo artículo 10 disponía que el Perú formaba parte integrante del territorio de la monarquia española; en segundo lugar, porque las Cortes de Cadiz. estaban integradas -entre otros-por nueve peruancs, que representahan al Perú; y, en tercer lugar, por la notable influencia que tuvo en las primeras constituciones del Pe$\mathrm{n}$, inchuso en materia de organización del Estado y protección de los derechos humanos.

Ia Constitución de Cadiz establecia que "Hil chieto del Gobierno es la feficidad de la nación, puesto que el fin de toda sociedad politica no es otro que el bienestar de los individues que la componen" (articulo 13), siendo tla nación ' la reunión de codos los expañoles "de ambos hemisferios" (artículo 15, asimesmo, "la soberania reside esencialmente en la nación y por lo tanto pertenece a ésta, exclusivamente, el derecho de estahlecter sus leyes fundaneritales" Grisculo 3). No cabe duda de que la Constitución otorgaba los mismos derechos a todos los ciadactanos de los territorios de ambos hemisferios, Europa y América. A mayor abundamicnto el articulo 5 indica. ba, en su primer parrafo, que "son españokes todos las bombres liberes nacidos y avecinados en los dominios de les Espantas y los hijos de estost' $y$ el articulo 10 señalabe los territorios que comprendia España: la América septentrional, Nueva España con la Nueva Galicia y la Península de Yucatán, Guatemala, prowincias internas de Oriente, provinctas internas de Occidente, la isla de Cuba con las dos Floridas, la parte espanola de la isla de Santo Domingo, y la isla de Puerto Rico con las demás adyacentes a éstas $y$ al continente en uno y otro mar. En Iu América meridional, la Nueva Granada, Venezuela, Pero, Chile, provincias del Río de la Plata y todas las islas adyacentes en el mar Pacifico y Atlántico y, en el Asia, las islas Filipinas, mencionándose tambiên las islas Canarias y territorios de África.

La Constitución de 1812 establece la división de las poderes del Fstado: las Cortes ejercen el Poder Legislativo (articu. lo 15) y estín conformadas por diputados elegidos por todos los ciudadanos, de ambos hemisferias, sobre la misma base: un diputado por cada 60 mil personas (articulos $27-29$ y 31 . Fl Poder Ejecutivo lo ejerce ef rey (artículos 169-170); sin embargo, la autoridad del fey no es absoluta, estando sujeta a las restriociones contempladas por el articulo 172, entre las cuales cabe destacar la expresada en el inciso undécimo:

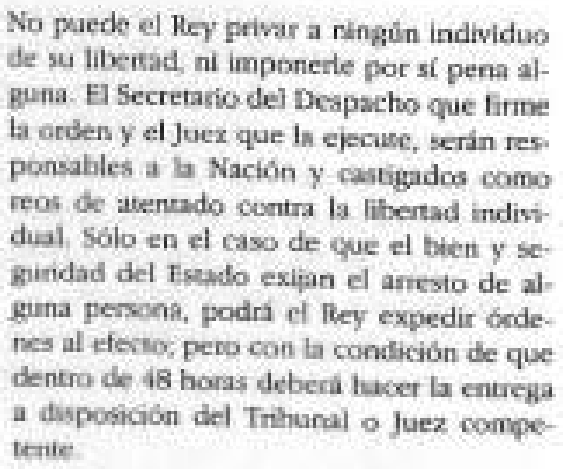

Al tomar posesión de su cargo, el rey delyia comprometerse, bajo juramento, a respetar la Constitución, declarando: 
-. respetaré sober todo la libertad politica de la Nación y la personal de cada indivi: duox y si en lo que he jurado, o parte de ello, lo conerario hiciere, no debo ser obedecida, antes aquello en que contaviniere, sea nulo $y$ de ningún valor (artículo 173).

\section{La Constitucióa de Cádiz declara que:}

la religjón de la Nación española es y será perpetuamente la Católica, Apostólica, Rormana, Onica verdadera. la Nación la protege por las leyes sabias y justas, y prohibe el excercicio de cualquiera cora carticulo 12).

La Constitución garantiza la libertad, la propiedad $\mathrm{y}$ los demás derechos legítimos de vodos los individuos" para lo cual debe dictarse leyes "sabias y justas" (artículo 4); igualmente garantiza a todos los ciudadanos, la libertad "de escribir, impaimir y publicar sus ideas politicas sin necesidad de licencia, revisión o sprobación alguna anterior a la publicación, bajo las restricciones y responsabilidades que establexcan las leyes" (articulo 371).

Se garantiza tambièn que no podrá ser allanado ningưn domicilio "sino en los casos que determine la ley para el buen orden y seguridad del Estado (articulo 306 ).

En la administración de justicia se reconoce ganartias a los detenidos y procesadas: "nadie puede ser detenido sin una sumaria previa que lo justifique $y$ sin manda. miento del Juez, que se notificara en el acto mismo de detención" (articulo 287); "el detenido debe ser presentado al Juex para que éste le reciba declaración, dentro de las 24 horas (anticulo 250 ); la declaración feferida sera sin junamerito "que a nadie ha de tomarie en materias criminales sobre becho propio' (articulo 291); despues de recibida la declaración, si el juez dispusiere el arresto, "se proveerd auto motivado, notificindose al arrestado $\gamma$ al alcayde, sin cuyo requisito no adrnitira el alcayde a ningùn preso en calidad de tal, bajo la más es. tricta responsabilidad" (artículos 293 y 360); "la contravención de tales preceptos por el Juez o el Alcayde, los hará pasibles de sanción poe detención arbitraria (artículo 299); "el proceso será público de alli en adelante" (artículo 302) y "no se usará nunca del tormento ni de las apremios" (articulo 303).

La Constitución de Cádiz autociza la suspensión de ganantís relativas a la administración de justicia, inchuso el arresto de personas, si circunstanclas extraordinarias de seguridad del Estado lo exigen; debiendo la suspensión de garantas ser decretach por las Contes, indicindose el plazo, asi como el territorio en que sea efectiva (articulo 306 ).

También mandaba que "en todos las pueblios" se estableciesen escuelas de primeras letras, para enseñar 'a leer, escribir y contar", asi como el catecismo y las "obligaciones civiles (artículo 336); igualmente, disponí la creación de universidades y centros de enseranza "de ciencias, lineratura y bellas artes" (articulo 367 ).

La Constitución encomendaba a las ayuntamientos -municipalichades- "la policia de salubridad y comodidad" (articulo 321 , inciso 1); el cuidado de los hospicios, casas de expósitas y demás establecimientos de bencficencia (artículo 321 , inciso 6) c, igualmente, la promoción de la agricaltura, ta industria y el comercio, "para beneficio de los pueblos" (articulo 321 , inciso 9).

Asi coano establece derechos y garantas, senala también deberes a los ciudada: nos: el amor a la patria, y "asimismo ef ser justos y beneficos" (articulo 6): "obedecer la Constitución y las leyes y respetar a las autoridades" (articulo 7), todo ciudadano, sin distinción algena, debe contribuir en proponción de sus haberes para los gastos del Estado (ariculo 8), y "defender la pa- 
tria con las armas, cuando sea llamado por la ley" (articulo 9).

La Constitución, finalmente, establece que todo ciudadano puede acudir ante las Cortes $\mathrm{o}$ ante el rey, para "reclamar la observancia de la Constícuclón" (articula 373), y que las Cortes "pondrain el conveniente remedio" $y$ harin efectiva la responsabilidad de quienes hubieran contravenido la Constimución (articulo 372).

Si pretendieramos juzgar la Constitución de 1812 , según los criterios actuales en materia de teoria del Estado, derecho constitucional y politico, asi como en materia de derechos humanos, obviamente encontrariamos numerosas amisiones y limitacio nes. Pero la Constitución de Cadiz debe ser juzpada conforme a la síuación politica, social y cultural de 1812. Y no hay duda de que, en su dia, significó un nocable desarollo politico y juridicos preciss que la soberanía radica en la nación, en el conjunto de ciudadanos; y no en el rey (antículos 1 y 3) y estableció la separación de los poderes del Estado, fecogiendo los avances del pensamiento juridtico de la segunda $\mathrm{mi}$ tad del siglo XVIII: proclamá también los derechos ciudadanos e introdujo oomas que permitian la libertad de los esclavos "a las que se distinguen por su tatento, aplicación y conducta" anticipandase así al Gongreso de Viena celebrado durante Jos años 1814 y 1815 , que adep 0 los primeros acuerdos internacionales que condujeron a la proscripción de la oprobiosa institución de la esclavitud.

\section{PSTATUTO PROVISIONAL.}

Dictado por el general José de San Martin el $\mathrm{\theta}$ de coctubre de 1821 .

Al asamir San Martin el mando del Perú, uno de sus primeros actos fue el de dictar una ley constitucional a la que llamo "Estatuto Provisional", en virtud del cual se hizo cargo de "la suprema potestad directiva de los departamentos libres del Perú... sus facultades emanan del imperio de la necesidad, de la fuerza de la tazón y de la exigencia del bien público" (sección 2, artículo 1). Se trataba de un poder absoluto en los aspectos legislativo y ejecutivo; al Poder Judicial en cambio, correspondia a la Alta Calmara de Justicia y juzgados subalternos (sección 7, articulo 1); no obstante, el estatuto cuictó de asegurar ciertos derechos elementales a tudo ciudadano: derecho a conservar su honor, libertad, seguridad, propiedad $\gamma$ existencia. El estatuto señalaba tantaién que a nadie podia privarse de estos derechos sino por decisión de autotidad competerte. En caso contranio, el interesado podía reclamar contra el Gobierno (sección 8, articulo 1). Se garantizaba tambien la inviolabilidad del domicilio, "que madie podrá allarar sin una orden expresa del Gobierno*. Igualmente, se garantizaba la libertad de imprenta (sección 8 , articulcos 2 y 4 ).

El estatuto proclama que la religión del Estado es la canćlica, apostólica y romana disponiendo que cualquier ataque en püblico o en privado a sus dogmas setíi "severamente castigado" (artículo 1). Nadie podra ser funcionario póblico si no profesa la religión catdica (articulo 3). Sin embargo, quiknes profesen ctras religiones cristianas, distintas de la catolica, pacde obtener permiso del Gobierno "para usar el derecho que le compete, siempre que su conducta no transgreda el orden público" (articulo 2 ).

Las limitaciones del estaruto, en mareria de derechos humancs, asi como la amplitud de las facultades conocdidas al Gobietno, tienen que ser jurgados en su cootexto histórico: la situación de betigerancia entre realintas y patriotas llevo a San Martin a astumir amplias facultades de gobierno, 3 
fin de que nada pudiera oponerse a su objetivo principal: la independencla de la patria.

\section{BASES DE LA CONSTTIUCIÓN POLITICA}

Aprobadas por el Congreso Constituyente y promulgadas el 16 de diciernbre de 1822, tienen objetivos permanentes y ya no el caricter provisional del estatuto anterior. Asi, las bases establecen que la soberania reside en la nación (articulo 2); que el gobierno es popular y representativo (articulo 4); que rodos los ciudadanos deben concumir a la elección de sus representantes (artículo 6); y que se consagra la división de las poderes: Legislativo, a cargo del Congreso; Ejecutivo, "a cargo de quienes lo ejerzan", de las ministros de Estado y el Poder Judicionaric. La religión catclica, apostolica y romana es la oficial, con exclusión de cualquier otra (artículo 5).

En materia de derechos bumanos, las Bases de la Constitución protegen la libertad de los ciudadanos, la libertad de imprenta, la seguridad persanal y la del domicilio; la propiedad, la inviolabilidad de la correspondencia, la igualdad ante la ley, la prohibición de penas crueles e infamantes; la abolición del comercio de escla. vos y el derecho individual de presentar peticiones y recursos al Congreso y al Gobierno (articulo 9).

Auncioc la guema de independencia no habia concluido al pronolparse las Bases de la Constitución, encontramas un natable avance juridico en este instrumento: se elimina el poder absoluto del Jefe del Estado, proclamándose el principio de la divi. sión de poderes y los derechos individuales, advirtiendose, sin embargo, la falta de protección de tales derechos (artículo 9).

\section{CONSTrTución POIfrTCA DE 1823}

Dictada poc el Congreso Constituyente fue promulgada por el presidente Jasé Berfardo de Tagle el 12 de noviembre de 1823.

Es la primera Constitución, propiamente dicha, del Perú independiente. Abarca los diversos aspectos de la organización politica del Estado: reitera que el Perú es un Estado independiente (articulo 2); que la soberania reside en la nación (artículo 3), y reitera la división de los tres poderes del Estado: Legislativo, Ejecutivo y Judicial, en un sistern de gobierno popular y representativo (articulos 27-2B); reitera que la religión cxtólica es la oficial, con exclusión de cualquier ocra (artículo 8 ).

En materia de derechice humanos ser̃ala que " $\$ nación no tiene facultad para de cretar leyes que aternten contra los derechos individuales" (articulo 5).

Señala que "nadie nace esclavo en el Peru' y prohibe el comercio de esclavos (artículo 11).

Declark como inviolables los siguientes derechos: la igualdad ante la ley, la liberfad civil, la seguridad personal y la del domicilio, la propiedad, el secreto de las cartas, la libertad de impreata, la libertad de la agricultura, industria, comercio y mincfia conforme a las leyes, 7 el derecho individual a presentar peticicones o recursos al Congreso o al Gohiemo (articulo 193).

Para garantizar la vigencia de estos de rechos, la Constitución establece que todos los peruanos pueden presentar reclamos ante las autoridades, siendo un deber de Estas respetarlos y "hacerlos guardar por todos los medios que estén en la esfera de las atribuciones de cada una de ellas* (articulo 1949. 


\section{CONSIrTución vTrAuciA DE 1826}

Promulgada por el presidente Andrés de Santa Cruz el 30 de noviembre de 1826 , otorga amplias facultades al general Simón Bolivar, que fue nombrado Presidente Viralicio de la República; sin embargo, esta Constimución reconoce la división de los poderes Legistativo, Ejecutivo y Judicial, con las funciones que les corresponde, reiterando que ha soberanía emana del pueblo y que el gobjerno es democratico y representativo, Reilera tambien que la religoón católica es la oficial, pero no excluye a las demás (articulo 6).

En materia de derechos humanos, la Constizución Viralicia garantiza a todos los peruanos b libertad civil, la seguridad individual, ta propiedad, b igualdad ante la ley (articulo 142), la libertad de pensamiento y de difusión de ideas $y$ la libertad de imprenta (articulo 143), asimismo, b inviob. bilidad del domicilio (anticulo 145); la li. bertad de permanecer o salir del territorio nacional (articulo 144); $y$ la libertad de trabajo, industria y comercio (articulo 148).

Señala también que el Presidente no puede privar de libertad a ningún peruano, ni imponer penas; y que, en caso de arres. to, el acusado debe ser puesto a disposición del juer, dentro de las 48 horas (articulo 86).

La Constitución Visalicia imponia tambièn deberes a los peruanos: Respetar la Constitucion y las keyes y obedecer a las autoridades; contribuir a los gastos publicos, as l como sacrificar los bienes y "la vida misral' cuando lo requiera el bien de b Repubilica; y velar por la conservación de las libertades públicas (artículo 12). No se menciona la esclavitud, pero al sentalarse como peruanos a todos los aacidos en el Penu (artículo 11) y ptecisarse que todos los peruanos son iguales ante la ley (articulo 142), se infiere que la Constitución no admite la esclavitud.

Se advierte tambien que exta Constitución, como las anterioñes, señala los deberes y derechos de los peruanos, pero nada dice sobre los extranjeros residentes en el pais.

\section{CONSTITUCión DE 1828}

Dictada por el Congreso Constituyente y promulgada por el presidente José de ta Mar el 18 de marzo de 1928

Como las anteriores, esta Constitución sen̂ala que el gobierno de la nación es popular y representativo, delegindose el ejercicio de la soberania a los poderes Legislativo, Ejocutivo y Judicial (articulos 7-8). La religión católica es la religión oficial, no permitiéndose el ejercicio de otra alguna (articulo 3).

Garantiza la libertad civil, la seguridad individual, la igualdad de los ciudadanos ante la ley, así como la propiedad (articulo 149): señala, también, que "nadie nace esclawo en la República" y que "tampoco entra de fuera ainguno que no quede ibre" (articulo 152).

Otros derechos reconocidos por la Constitución son: la libertad de pensamiento y de difusión de ideas, así como la libertad de imprenta (articulo 153), el se. creto de la correspondencia (articulo 156); la inviolabilidad del domicilio (artículo 156); la libertad de todo peruano para per. manecer o salir del territorio de la Republica (articuilo 154); la libertad de trabajo, industria y comercio (articulo 166), y el derecho de petición anae el Congreso o el Ejecutivo (articulo 168).

Proclama la independencia del Poder Judicial y establece determinadas ganantias 
para b administración de justicia: prohibe revivir procesos fenecidos (articulo 161); prohibe la aplicación retroactiva de la ley (articulo 151); prohibe también "toda severidad invitil a la custodia de los presos" y serala que las circeles son lugares de seguridad y no de casigo (artículo 163).

En cuanto a derechos sociales y culrutales, garantiza la instrucción primaria y gratuita y promueve el establecimiento de centros de enseinanza de ciencia, literatura $y$ arte, asi como de establecimientos de piedad $y$ beneficencia (articulo 171).

Finalmente, impone a los ciudadanos el deber de proteger los derechos civiles y politicos "por medio de las armas y de las contribucianes en razón de sus fuerzas $y$ de sus bienes' (articulo 172).

\section{CONSTITUCION DE 1834}

Dictada por la Convención Nacional y pronulgada por el presidente tuis Jose Orbegoso el 10 de junio de 1834.

Repite esta Constitución que la nación peruana es independiente (articulo 1); su forma de gobierno es popular y represen. tativa (articulo 7), y delega el ejercicio de la soberania a los poderes Legislativo, Ejecutivo y Judicial (articulo 8). Reitera que la religón católica es la religión oficial, no permitićndose el ejercicio de otra alguna (articulo 2).

Estublece que todos las peruanos son iguales ante la ley (articulo 158), reiterindo, como la Constitución anteriot, que "nadie nace esclavo en el territorio de la República, ni entra ninguno de fuera que no quede libre' (arriculo 1460.

Ganntixa b libertad de pensamiento y difusión de ideas, asi como la libertad de imprenta (articulo 147), asimismo, el secreto de la correspondencia (articulo 156); la inviobabilidad del domicilio (articulo 155) y la libertad para permanecer o salir del pais, (articulo 148), salvo sentencia judicial que ordene la expatriación (artículo 149), Garantiza también el derecho de propiedad (articulo 161) y la libertad de trabajo, de industria y de comercio (articulo 162). Reconoce el detecho de petición al Congreso $y$ al Ejecunivo (articulo 164).

En materia judicial, seǹala que nadie puede set condenado sino en juicio legal (articulo 145). Nadie puede ser arrestado $\sin$ mandato judicial motivado (articulo 151), salvo en flagrante delito (articulo 152), o par arden del Ejecutivo, fundada en razontes de seguridad, en cuyo caso el detenido debe ser puesto a disposición del juez dentro de las 48 horas Garticulo 86, inciso 5). Se prohibe toda severidad inútil a la custodia de los presos, señalindose que las carceles son lugares de seguridad y no de custigo (articulo 157); como medio de protección de los derechos civiles establece que todo peruano puede reclamar ante el Congreso o el Poder Fiecutivo las infracciones a la Constitución" (articulo 165).

No se incluye previsiones sobre derechos de los extranjeros.

\section{CONSTITUCION DE HUANCAYO DE 1839}

Dictada pot el Congreso General y pro. mulgada pot el presidente Agustín Gamara, en Huancayo, el 10 de noviembre de 1839.

Comso las constiruciones anteriores, senala que la nación peruana es indepen: fiente (articulo 2), que su forma de gobierno es popular y representativa (artícula 12) y que la soberanía es ejencida por los poderes Legislativo, Ejecutivo y Judicial 
(articulo 13), y reitera que la religión católica es la oficial, no permitiendose el ejercicio de otro culto (articulo 3).

In materia de derechos humanos, la Constinución de Huancayo señala que todos los peruanos son iguales ante la ley (articulo 160), y que "nadie nace esclavo en la Republica" (articulo 155); sin embargo, no recogis ha norma de las constituciones anteriores sobre manumisión de las esclavos que ingresasen al Perú.

las demás garantias individuales contenidas en las constituciones anteriores son recogidas en la de Huancayo libertad de pensamiento, de difusión de ideas y de imprenta (artículo 156), inviolabilidad de la correspondencia (articulo 159); del domicilio (articulo 158); libertad para permanecer a salir del territorio (aniculo 157); Liber. tad de trabajo, industria y comercio (articalo 169) y derecho de petición al Congreso y al Ejecutivo (articulo 171). En materia judicial repite la prohibicion de "toda severidad invitil a la custodia de las presos" y seala que "las circeles son lupares de seguridad y no de castigo" (articulo 165), indcando tambiến que "ninguna ley tiene fuersa retroactiva" (articulo 154), Establece la publicidad de los juicios, y dispone que la sentencia debe ser motivada (articulo 125). Prohibe, también, revivir procesos concluidos (artículo 129).

Garantiza la instrucción primaria gratui. ta, la instalación de centros de enseñanza de "cienciss, literatura y arte", así como de "establecimientos de piedad y beneficencia' (artículo 174).

Como medio de protección de las garantias individuales establece que "Todo peruano puede reclamar anse el Congreso o el Poder Fjecutivo, las infracciones a la Constitución' (artículo 177).

Finalmente, dispone que todo ciudacts. no tiene el deber de contribuir con el Fatado mediante las armas y los impuestos, en proporción a las fuerzas y los bienes de cada uno (articulo 175).

Un avance notable de la Constitución de Huancayo consiste en reconocer a los extranjeros los misenos derechos civiles que a los peruanos (artículo 178).

\section{ESTATUTO PROVISORIO DE 1855}

Dictado por la Convención Nacional y promulgado por el presidente Ramán Castilla el 26 de julio de 1855 .

Como los estatutios de $5 a n$ Martin y Bolivar, el Estatuto Pravisorio de 1855 es autoritario, concediendo amplias facultades al presidente prowisorio de la República: el Poder Legislativo queda a cargo de la Convención Naciomal de cuyas funciones nada dice el estututa El Poder Judicial, cuyos miernbros son noenbrados por el presiden. te prowisorio, tiene a su cargo la administración de justicia (articulo 1, incisos 6-7; ar ticulo 2, inciso 3).

Sefiala el estatuto que todos los peruanos son iguales ante la ley (articulo 8 , inciso 7), agregando que "nadie es esclaryo en la Republica" fartículo 8 , inciso 2 ) can lo que se consagra definitivarnente en el Perii, en una nocma de jerarquia oonstitucional, la abolición de la esclavitud. En efecto, no se linuta esta norma a indicar que nadie "nace" esclava en el Peru, o que quienes "ingresen" al Pend quedan libres, sino que declara que nadic "es" esclavo en el Peru. Anteriomnente, los nacidos esclavos habian continuado en esta situación. Pero con el Estanuso Provisorio de $1855 \mathrm{la}$ esclavitud quedo definitivamente abolixla en el Perú

Otros derechos indisiduales garantixa. dos por el ertatuto suet: la libentad de pensamiento, de difusión de ickeas y de imprenta (articulo 8 , inciso 3 ), el secreto de 
la correspondencia (articulo 8, inciso 6); la inviolabilidad del domicilio (artículo 8, inciso 5); la libertad de permanecer o salir del territorio (antículo 8, inciso 4). En materia judicial, repite la probibición de "toda severidad inútil a la custodia de los presos" y seriala que las cárceles son lugares de teclusión y no de castigo (articulo 12), indicando también que "ninguna ley tiene fucrza retraactiva" (articulo 8, inciso 1); garantiza la libertad personal cualguier persona detenicla debe ser puesta a disposición del juez dentro de las 24 hotas (artioulo 2, inciso 4). Garantiza también la libertad de trabajo e industria (artículo 16), y cl derecho de petición individual o colectiva (artículo 19).

El estatuto garantiza la instrucción primaria gratuita para todos los habitantes, la instalación de centros de ensefianza de ciencias, literatura y arte, asi como de "escablecimientos de picdad y beneficencia" (artículo 1, inciso 22; y articulo 21).

Establece el deber de los peruanos de concurrir al servicio de amas para la defensa del Estado (articulo 22).

Asimismo, concede a los extranjeros "todos los detechos concernientes a la segurichd de sus personas y de sus bienes, $y \geq$ la libre administractóo de éstos" (articulo 15).

El caricter zutoritario del estatuto se pone de manifiesto al no incluir mecanismos de protección para el caso de violación de las garantias individuales. No obstante, su mérito fundamental cstá dado por la abo. lición definitiva de la exciavitud, que las constituciones posteriores del Peri recogen.

\section{CONSTITUCIÓN DE 1856}

Dictada por la Convención Nacional el 13 de octubre de 1856 y promulgada por el presidente Ramón Castilla el 16 del mis. mo mes $\mathrm{y}$ año.

La Constitución de 1856 declara que la naciớn peruana es la asociación politica de rodos los pervanos (artículo 1), que es libre e independiente (articulo 2) y soberana (articulo 3). Il gobiemo de la Repóblica es democritico y representativo (articu. lo 41) y se ejerce modiante los poderes Legislativo, Ejocutivo y Judicial (articulo 42 ). Asimismo, reitera que ta religión catolica es la ofichal y que no se permite el ejerclcio de ninguna otra (artículo 4).

Es el primer texto constitucional pervano que protege el derecho a la vida y prohibe la pena de muente: "La vida humana es imviolable; la ley no podrá imponer la pena de muerte" (artículo 16); consagra la igualdad ante la ley (artículo 31) y reitera la noma del Estatuto Provisorio de 1855 sobre la abolición de la esclavitud: Nadie es esclavo en la Repüblica" (articulo 17). Garantiza la libertad de imprenta (articulo 20), el secreto de la conrespondencía (articulo 21) la inviolabilidad del domicilio (articulo 30); prohibe la expatriación, salvo por sentencia ejecutoriada, garantía que otras constituciones no contemplaron (articulo 19); gamantiza la libertad de asociación, "en público o en privado, sin comprometer el orden público' (artículo 28), la libertad de trabajo e industria (articulo 22), la propiedad (articulo 25), y el derecho de petición individual o colectiva (articulo 29).

En materia de garantias judiciales, establece que nadie puede ser detenido sin mandato escrito del juez "o autoridad encargada del onden publico' debiendo ponerse al detenido a disposición del jurgado dentro de las 24 horas (articulo 18); indica que "ninguna ley tiene efecto retroactivo" (articulo 15). Los juicios deben ser públicos y las sentencias motivadas (arlículo 128), no pudienido revivirse procesos fenecidos (articulo 130). 
Establece la acción popular contra los jueces por prevaricato, cohocho $y$ violación de las garantias individuales (artículo 131). Y para cautelar el cumplimiento de las leyes, se crea el cargo de Fiscal de la Nacion, asi como los de fiscales $y$ agentes fiscales (articulos 132-133). Asimismo, se faculta a todo perusno para reclamar ante ef Congreso, el Ejecutivo o cualquier autoridad competente, por infracciones a la Constitudion (articulo 14).

Por otra parte, garantiza la instrucción primaria gratuita, y los establecimientos publicos de ciencizs, artes, piedad y beneficencia (artículo 23), introduciendo tambućn la libertad de ensernanza "para quienes ofrezcan garantias de capacidad y moralidad: y bajo la inspección de la autoridad (articulo 24).

A los extranjeros se les reconoce el derecho a adquirir propiedad tertitorial, en las mismas condiciones que los peruanos (articulo 26). No hay referencia exprese a otros derechos de las extranjeros, aunque ta amplitud del texto constitucional respecto al derecho a la vida y a la libertad individual, no deja duda de que protege tanto a los peruanos como a los extranjeros, al sehalar que se probibe la pena de muerte, que "nadie es esclavo en la Republica, que "nadie puede ser arrestado sin mandato del juez", etc.

\section{CONSTTUCAON DE 1860}

Dictada por el Congreso el 10 de noviembite de 1860, y promulgada por el presidente Ramón Castilla el 13 del mistuso mes $y$ aho.

Introduce ciertas reformas a la Constitucoón de 1856, pero manteniendo lo esencial de estak, Reitera que la nación peruana es la asociación politica de todos los pe- ruanos (artículo 1); que es libxe, independiente (articulo 2) y soberana (articulo 3). Ul gobiemo es republicano, democraitico $y$ representativo (articulo 42), y se ejerce mediante los poderes Legislativo, Ejecutivo y Judicial (articulo 43).

Reitera que "La nación profess la religión catolica, apostólica y romana: el Estado la protege y no permite el ejercicio público de otra alguna' (artículo 4). Mantiene el principio de protección a ha vida "contra toda injusta agresión", autorizando la pena de muerte para el homicidio calificado (artículo 16); declara la iguaklad ante la ley (artículo 32) y la abolición de la esclavitud: "No hay ni puede haber esclawos en la República" (articulo 17), fórmula con la que parece haberse buscado dar mayor énfasis y certiclumbre que con la expresión de la Constitución anterior.

Garantiza la libertad de imprenta (articulo 21), el secreto de la correspondencia (artículo 12), la inviolabxlidad del domicilio (articulo 31), la prohibición de la exparriación salvo por sentencia ejecutoriada (articulo 20). Asimismo, la libertad de asociaciôn pacifica, en público o en privado, sin comprometer el orden püblico (articulo 29), la libertad de trabajo e industria (ar. tículo 23); la propiedad (artioulo 26) y el derecho de petición individual o colectiva (articulo 30).

Acerca de las garanúas judiciales, la Constitución de 1860 establece que nadie puede ser detenido sin mandato escrito del juez "o autoridad encargada del arden público" debiendo, en todo caso, ponerse al detenido a disposición del juzgado dentro de las 24 horas (articulo 18); también sehala que "ninguna ley tiene fuerza ni efecto retroactivo' (articulo 15), que los juicios de: ben ser publicos y las sentencias mocivadas (articulo 127), no pudiendo revivirse procesos fenecidos (articulo 129). Recoge tamhién la nomm de anteriores constituciones, 
de prohibir toda severidad innecesaria a la custodia de los prescos, indicando que las carceles "son lugases de reclusión y no de castigo" (artículo 19).

Mantiene la acción popular contra los jueces por prevaricato $y$ violación de las garantias individuales (artículo 130). Incorpora a los fiscales al Poder Jucticial, tanto en la Corte Suprema como en las instanclas inferiores (articulos 125 y 127 ), con lo que la Piscalfa perdió la autconomia que le ctorgata la Constitución de 1857, desapareciendo, además, el cargo de Fiscal de la Nación, que sólo reaparece 122 años después, con la Constitución de 1979. Se suprime también la faculard que concedia la Constitución de 1857 a todo peruano, para reclamar ante el Congreso, el Ejecutivo u otra autoridad competente, por infracciones a ba Constirución.

Reitera que se garantiza la instrucción primaria gratuita y el fomento de los esta: blecimientos públicos de ciencias, artes, piedad y bencficencia (articulo 24), reconociendo también la libertad de enseñanza para quienes ofrezcan garantias de capacidid y moralidad, y bajo la inspección de la autcrichad (articulo 24).

A los extranjeros se les reconoce el derecho a achquirif propiedad territorial, en las mismas condiciones que los peruanos fartículo 28). Por lo tanto, la protección a la vida y las libertades fundamentales alcanza no sólo a los peruanos, sino "a todos"; poe lo tanto, no debe considerane el articulo 28 como ùnica norma referente a la proteccide de derectos de los extranjeros, sino coeno complemento de las demás normas.

\section{Covstructón DE 1867}

Fue sancionada por el Congreso Constituyente y promulgada por el pessidente provisorio Mariano Ignacio Prado el 29 de agosto de 1867.

Reitera que la nación pervana es libre, independiente $\mathrm{y}$ soberana (articulo 1). E gobiemo es republicano, democritico y representativo (articulo 43) y se ejerce mediante los poderes Legislativo, Ejecutivo y Judicisl (articulo 44), Reitera que "la mación profesa la religión católica, apostólica y ramana. El Estado la prosege y no permite el ejercicio público de otra alguna' (articulo 3).

Como la Constitución de 1858 , dedara que la vida humana es inviolable y prohibe la pena de muerte (articulo 15). Declara la igualdad ante la ley (articulo 30 ) y la abolición de la esclavitud (articulo 16).

Asimismo, garantiza la libertad $d c$ imprenta (artículo 20), el secreto de la correspondencia (articulo 21), la inviclabilidad del domicilio (anticulo 29), la prohibición de la expatriación, salvo por semiencia cjecutoriada (articulo 19); garantiza la libertad de asociación "en pulblico o en privado" farticulo 27), la libertad de trabaio, industria y profesion (articulo 22), la pocpiedad (articulo 25) y el derecho de petición indivictual o colectiva (articulo 28).

Como garantias judiciales, reivera que nadie puede ser detenido sin manclato del juez o de las autoridades competentes, salvo en flagrante delito, debiendo ser puesto el detenide a dispocicición del juez dentro de las 24 horas (artículo 17), precisando tambièn que la ley no tiene efecto retroactivo (articulo 14), que los juicios deben ser publicus y las sentencias motivadas Garticulo 125), no pudiendo revivirse procesos fenecidos (articulo 127). Reitera b prohibición de toda severidad innecesaria con las presos, indicando que las circeles son lugares de reclusión y no de castigo (artículo 18 ).

Mantiene la acción popular.contra las jueces por prevaricato, cohecho y violacion de las garantias individuales (articulo 
128); mantiene también a los fiscales en la misma forma que la Constitución de 1860 (artículo 120) pero, como ésta, tampoco autoriza les reclamos ante el Congreso o el Ejecutivo por infracciones a la Constitución.

Como las constituciones anteriores, $\mathrm{Ba}$ rantiza la instrucción primaria gratuita y el fomento de los establecimientos públicos de ciencias, arte, piedad y bencficencia (articulo 23), asi como la libertad de enseAanza (articulo 24).

Respecto de los extranjeros, mantiene el régimen de las constituciones de 1856 y 1860 (artículo 2B).

\section{ESTATUTO PROVISORIO DE 1879}

Fue dictado por el Jefe Supremo de la República, Nicalás de Piérola, el 27 de diciembre de $\operatorname{tg79}$ y tuvo vigencia hasta agoeto de 1881, restableciéndose entonces la Constitución de 1857 .

Asi como el Consejo Municipal o Cabildo de Lima encargó el mando supremo de la República a don José de San Martin el 23 de julio de 1821, asi también, el mismo Consejo Municipal de Lima, en el momento más grave que ha vivido la Repúbtica - los días de la guerra con Chile- encontrándose yacente el Gobierno, llamó a Ni: colás de Piérola y le encomendó presidir el Gobierno Nacional.

El Estatuto Provisorio proclama que th sobcranía y la independencia son el fundamento de la vida politica y social del Peru (articulo 1); al mismo ticmpo mantiene el régimen de la Constitución de 1857 acerca de la religión catalica como religión oficial (articulo 3).

El estatuto garantiza la seguridad personal, la libertad, el honot, la igualdad ante b ley y la propiectad ssimismo, ta lbertad de imprenta, "quedando proscrito el anonimo"; los delitas cometidos par medio de la imprenta no cambian su naturaleza, siendo por tanto sometidos a los tribunales comunes, Garantiza tumbién la libertad de inclustria, "en cuanto no sea dañosa"; la libertad de asociación y el derecho a pedir justicia o gracia, inctivicual o colectivamente (articulo 7 ).

Estableco que "durante la presente gue$\mathrm{ma}^{\prime \prime}$, los siguientes delitos scrán juzgados milizarmente y penados con la pena capital: la traición a la patria, la cobardia e insubordinación militares, la deserdión en campaña, el peculado, la prevaricación, el cohecho, la defraudación de bienes puiblicos, el homicidio premeditado y alevoso y el bardalerismo (articulo 8), Tambièn garantiza la independencia del Poder Judicial, velando por la pronta y exacta administracán de justicia (articula 5).

\section{CONSTrTUCION DE 1920}

Fue dictada por la Asamblea Nacional cl 27 de diciembre de 1919 y promulgada por el presidente Augusto B. Leguia el 18 de enero de 1920.

Reitera que "La nación peruana es la asociación politica de todos los peruanos" Garticulo 1); que la nación es libre e independiente (articulo 2); que la soberania reside en la nación, estando sa cjercicio encomendado a los funcionarios çac estabiece la Constitución (articulo 3). El gohierno es republicano, democrático y representative (articulo 68) y se ejerce niediante los poderes Legislativo, Ejecutivo y Judicial (artículo 69)

Asimisono, prodama que "la nación profesa la religión catclica, apostólica y romana. El Estado la protege" (articulo 5); ya no se prohibe, sin embargo, el ejercicio de otra 
religión como en las constitudones anteriores; mis aủn, la Constinución establece que nadie puede ser perseguido por razón de sus ideas o creencias (artículo 23).

Reitera el principio de protección a la vida "contra toda injusta agresión", limitando la aplicación de la pena de muerte a los casos de homicidio calificado y traición a la patria (artículo 21); reafirma la igualdad ante la ley (articulo 17) $\gamma$ la abolición de la esclavitud (articulo 22), con la misma fírmula de la Constitución de 1860: "No hay ni puede haber esclavos en la República".

Garantiza también la libertad de imprenta (articulo 34), el secreto de la corres: pondencia (articulo 32), la inviolabilidad det domicilio (articulo 31), la prohibición de la expatriación, salvo por sentencia ejecutoriada como establecfa la Constitución de 1860, agregándose "o por aplicación de la ley de extranjeriat (artículo 30 ). Igualmente, la lbertad de reunión pacifica, en público o en privado, sin comprometer el orden público (articulo 33 ), la libertad de trabajo (artículo 46), de comercio e indus. tria (articulo 45), de asociación (articulo 37) y de propiedad (articulo 38), asi como el derecho de entrar, transitar y salir del territorio nacional con las limitaciones establecidas por las leyes penales, sanitarias o de extranjeria (articulo 29).

Iin cuanto a garantias judiciales, la Constitución de 1920 establece que nadie puede ser detenido sin mandato escrito del juez. "o de las autoridades encargadas de conservar el orden póblico" debiendo el arrestado ser puesro a disposición del juez dentro de las 24 horas, autorizando la accion de halbeas corpus (articulo 2f) como medio de protección de la tibertad individual. El hábeas corpus, que aleanza aquí jerarquía constirucional, ya edistila en el Peiv, pues fue establecido por ley de 1897. dumante el segundo gobierno de Nicotas de Piérola.
Dispone también la Constitución de 1920 que "ninguna ley tiene fuerza ni efecto retroactivo" (artículo 20); que los juicios deben ser públicos y las sentencias motivadas (articulo 154), no pudiendo revivirse procesos fenecidos (articulo 155): Repite la norma de anteriores constituciones de prohibir toda severidad innecesaria a la custodia de los presos, indicandio que las círceles "son lugares de reclusićn y no de castigo" (artículo 27). Dispone que carecert de valor legal toda declaración arrancada por la violencia y que nadie puede ser condenado sino confonne a leyes preexistentes al becho impucado y por los jueces establecidos por la ley (artículo 26). Dispone también que no hay prisión por deudas (articulo 25). Y mantiene la acción popular contra los jueces por prevaricato, cohecho y viobaciôn de las garantias individuales, así como por la prolongación indebida de los procesos penales (articulo 157).

Se restablece la faculrad que concedia la Constitución de 1857 a todo peruano para reclamar ante el Congreso, el Ejecutivo, - cualquier autoridad competente, por infracciones a la Constitución (articulo 16). señalíndose tambièn que las garantias individuales no pueden ser suspendidas por ninguna ley o autoridad (articulo 35).

Garantiza la instrucción primaria gratuit2 para los varones y mujeres desde los seis atios de edad "para curyo efecto se establecerá una escuela primaria elemental para varcones y otra para mujeres, en cada capital del distrito": asimismo, se contempla el establecimiento de escuelas primarias de segundo grado, para cada sexo, en las capitales de provincia. Igualmente, el Fstado difundiri $\mathrm{l}$ ensenanza secundaria y superior, y los establecimientos de ciencias, artes y letras (articulo 530 . No se mantiene, sin embargo, la libertad de enschanza a que se referian las constituciones anteriones. 
Dispone también que el Estado fomentará "los servicios sanitarios y de asistencia pública, institutes, hospitales y asilos y cuidará de la protección $y$ auxilio de la infancia $y$ de las clases necesitadas" (articalo 55). Igualmente, establece que "El Estadio protegerí is la raza indigena y dictarí leyes especiales para su desarrollo y cultura en armonia con sus necesidades' (artículo 58).

Los extranjeros tienen los mismos derechos gue los peruanos, en cuanto a la propiedad, no pudiendo apelar a reciamaciones diplomáticas (artículo 39 ).

\section{CONSTITUCIÓN DE 1933}

Fue dictada por el Congreso Constituyente el 29 de marzo de 1933 y promulgatda por el presidente Luis M. Sanchez Cerro, el 9 de abril del mismo año.

Reilerando la formula de las cartas anteriores, la Constitución de 1933 establece que el Perú es República democriltica; que el poder del Estado emana del pueblo y se ejerce por los funcionarios, con arreglo a la Constitución y a las leyes farticulo 1). Se mantiene la división de los poderes del Fis. tado Legislativo (artículo 89), Ejecutivo (articulo 134 y ss.) y Judicial (articulo 2203.

la Constitución de 1933 garantiza la bibertad de prensa (articulo 63); los delitus que se cometan por medio de la imprenta serín juzgedos por los tribunales onclinarios (articulo 64); garantiza también el secreto de la correspondencia (arúculo 66), y la invichabilidad del domicilio (articulo 61); reconoce el derectio de reunión pacifica, sin armas $y$ sin comprometer el orden pubetico (articulo 62), declana que es libre el derecho de entrar, transitar $y$ salir del terri. torio nacional con las fimitaciones de las leyes penales, sanitarias y de extranjeria (artículo 67), asimismo prohibe la expertria- ción, salvo pos sentencia ejecutcriada o por aplicación de la ley de extranjeria (articulo 63). Reconoce la libertad de ascociación y de contrataciôn, que deben estar reguladas por la ley (articulo 27); asimismo, la liberad de trabajo, profesión, industria u oficio (articulo 42), disponiendo que los trabajadores deben participar en los beneficios de las empresas (articulo 45). La Constitución reconoce también el derecho de propiedad (articulo 29), que debe-ejercerse en armonia con el interés social (articulo 30. Reitera que los extranjeros estắn en la misma situación que los nacionales; en cuanto al derecho de propiedad, $y$ que no pueden apelar a reclamaciones diplomáticas (articulo 32).

La Constitución extiende la aplicación de la pena de muerte a los delitos de homicidio calificado, traición a la patria $y$ "todos aquellos que señała la ley' (artículo 54). Reitera el principio cle igualdad ante 12 ley farticulo 23) y, si bien el constituyente de 1933 como el de 1920 ya no consideró necesario referirse a la abolición de la esclavitud, en cambio, en ésta se establece que 'a nadie puede obligarse a prestar trabajo personal sin su libre consentimiento y sin la debida retribucion" (artículo 55). Dispone también que el Estado protege la religión catolica, apostólica y romana, agregando que "las demás retigiones gozan de libertad para el ejercicio de sus respectivoe culsos" (articulo 232); igualmente, garantiza la libertad de conciencia $y$ de creencia agregando que "nadie serí perseguido por razón de sus ideas" (artícula 59)

Como garantias judiciales, establece que aadie puecle ser deteriido sino por mandato "escrito y motivado" del juez competente o por las autoridades encangadas de conservar el anden público, salvo flagrance de lito, debiendo ser puesso el detenido a disposición del juez dentro de las 24 horas (articulo S6), estando prohiboda la prisión 
por deudas (articulo 58), Queda también establecido que la ley no tiene fuerza ni efecto retroactivos (articulo 25) y, por ende, nadie puede ser condenado sino con arreglo a una ley preexistente a la comision del hecho imputado como delito. Señala también que los juicios deben ser públicos y las sentencias motivadas (artículo 227), no pudiendo revivirse procescs fenecidos (articulo 228); asimismo, establece que el Estado indemnizará a las victimas de errores judiciales en materia criminal (articulo 320); se mantiene la acción popular para denunciar los detitos contra los deberes de función y otros que cometan los jueces en el ejercicio de sus cargos, o los funcionarios del Gobiemo al cjecutar resoluciones judiclales (articulo 231).

Autoriza la Constitución el derecho de petición individual y colectiva; sin embargo, no pueden ejercerlo los miembros de las Fuerzas Amadas (articulo 60). Autoniza también las reclamaciones ante el Congreso por infracciones a la Constitucican (atticulo 26); dispone igualmente que todos los derechos individuales y sociales reconocidos por la Constitución, dan lugar a la acción de hábeas corpus" (articulo 69). Sin embargo, cuando to exija la seguridad del Estado, el Elecutivo puede suspender por plazos procrogables de 30 dias, las garantias declaradas en el articulo 56 (arresto de personas), articulo 61 (inviolabilidad de domicilio), anticulo 62 (derecho de reunion) y articulo 67 clibertad para entras, transitar y salir del verritorio nacional); las demós garantias no pueden ser suspendidas.

La Constitución de 1933 dispone que "la dirección técnica de la educación corresponde al Estado" (artículo 71), siendo gratuita y obligatoria la ensenanza primaria (articulo 72), debiendo funcionar una es. cuela en todo Jugar cuya población sea de treinta alumnos; asimismo, habrí instrucción primaria completa en todas la capira- les de provincia y de distrito (articulo 73 ). El Estado fomenta la instrucción secundaria y superior con tendencia a la gratuidad (articulo 75), así como la instrucción técnica de los obreros (artículo 77). Igualmente, "el Estado fomenta y contribuye al sostenimiento de la educación preescolar y postescolar, $y$ de las escuelas para niños retardados o anormales (articulo 78). Es obligatoria la educación moral y civica del niño, inspirada en el engrandecimiento nacional y la solidaridad humana (articulo 74). Finalmente, se gananiza la libertad de cátedra (articulo 80).

Señala también la Constitución que "El Estado tiene a su cargo la sanidad pública y cuida la salud privada" (articulo 50); y dispone el establecimiento de un régimen de seguridad social para cautelar "las consecuencias econónicas de la desocupación, enfermodad, invalidez y muerte" Garticulo 48). Declara también que la ley protege "el matrimonio, la familia y la maternidad" (articulo 51), asi como la salud fisica, mental y moral de la infancia, especiatmente de los ninos en estado de abandono, enfermedad o desgracia (artículo 52).

\section{ESTATUTO REVOLUCIONARIO DE 1968}

E1 3 de ocsubre de 1968 se estableció un gobiemo militar que se prolongaria hasta el 28 de julio de 1980 . El primer acto del gobierno militar consistió en dictar un Estatuto Revolucionario, el cual establecía que el Presichente de la República seria de. signado por los tres comandantes generales de la Fuerza Armada, tenjendo el gobierno revolucionario la finalidad de transformar la estructura del Estado ha ciéndola más dirámica y eficiente", "promover a superiores niveles de vida compatibles con la dignidad de la persona huma. 
na, a los sectores menos favorecidos de la población, realizando la transformación de las estructuras económicas, sociales y culturales del pais", "moralizar al pais en todos los campos de la actividad nacional y restablecer plenamente el principio de au. toridad, el respeto a la ley y el imperio de la justicia", "imprimir a los actos de gobierno un sentido nacionalista $e$ independiente, sustentado en la firme defensi de ha soberanía y digrichad nacional" y "promover la unión, concordia e integración de los peruancs, fortaleciendo la conciencia nacional" (articulo 2).

La Constitución de 1933 y todas las leyes de la República, quedaron supeditadas al Estatuto de 1968 (articulo 5) y solo cran aplicables y continuaban vigentes, en tamo no fuesen contrarias al Estatuto Revolucionario.

\section{CONSTrTuCiÓN DE 1979}

La Asamblea Constituyente convocada por el presidente Francisco Morales Bermodez, redacto una nueva Constitución, la que fue promulgada el 12 de julio de 1979 , entrando en vigencia de inmediato parte de su artioulado, principalmente lo relaciomado con las elecciones y la estructura del muevo gobierno constitucional. Elegielo el arquitecto Fernando Belaunde Terry como Presidente Cansticucional, inicio su segundo gobierno el 28 de julio de 1980 y, en esa misma fecha, mando publicat la Constitución que alcanzó, asi, la plenitud de su vigencia.

La Constitución de 1979 señala que el Perú es una Republica "democrática y social, independiente y soberana, basada en el trabajo" siendo el gobierno "unitario, representativo y descentralizado" (articulo 79). El poder emana del pueblo y ae ejerce en su representación, con afreglo a la ley (artículo 81). Se mantiene la división de los poderes del Estado: Legislativo (anticulo 164 y ss.), Ejecutivo (articulo 201 y ss.) y Judicial (anticulo 232); además, se otorga autonomia al Ministerio Público (articulo 250), al que corresponde la defensal de la legalidad, de los derechos ciudadanos y de los intereses publicos, ante los tribunales; asimismo, actuar como defensor del pueblo ante la administración pública; igualmente, establece el Tribunal de Garantias Constitucionales (articulo 296), como órgano de control de la Constitución.

Setala la Constitución que ta persona bumana es el fin supremo de la sociedad y del Estado. Todos tienen la obligación de respetarla y protegerla' (artículo 1). Consecuente con ello, la Constitución de 1979 recoge rodos los derechos estipulados en el Pacto Internacional de Derechos Civiles y Politicos, Pacto Internacional de Derechos Econónicos, Sociales y Culnumales y la Convención Americana de Derechos Humanos.

Establece mecanismos judiciales para la protección de los derechios civiles y politicos (acción de hábeas corpus y acción de amparo) $)_{1}$ intsoduce una innovación en nuestro sistema constitucionah contra las resoluciones de la Corte Suprema, en materia de habeas corpus y acción de amparo, puede interponerse el recurso de casa. ción ante el Tribural de Garantias Constitucionales (articulo 298); más atin, agotada la jurisdioción interna con la resolución del Tribunal de Garantias Constitucionales, puede acudirse a instancias intemaciona. les: Camilé de Derechos Humanos, Comité para la Fliminación de la Disscriminación Racial, dentro del sistema de Naciones Unadas y Comision Interamericana de Derechos lfumanos, dentro del sistema repiomal; asimismo, la Constinución recanoce la competencia de la Conte Intesamerkana de 
Derechos Humanos (articulo 315 y disposición general $N^{2}$ 16). De este modo quedan consagrados dos sistemas de proteccion de los derechos civiles y politioas: uno interno y otro intermacional.

Un examen minucioso de cada noma de la Constitución de 1979 en materia de derechos humanos, excederia de las propósitos de este articula. Permitaseme, no obstante, referime a algunas de ellas.

La religión católica ya no es la religión oficial del Fstado como en las constituciones anteriores. Sin embargo, "Dentro de un régimen de independencia $y$ autonomia, el Estado reconoce a la Iglesia católica como elemento importante en la formación historica, cultural y moral del Perí. Le presta su colaboración. El Extado puede también es: tablecer formas de colaboración con ouras confesiones" (articulo 86). Asimismo, la Constitución declara que toda persona tiene derecho "A la libertad de conciencia y de religion, en forma individual o asociacta. No hay persecucióa por razón de ideas o creencias. El ejercicio de todas las confesiones es libre, siempre que no ofenda la mo. ral o altere el coclen público" (articulo 2, inciso 3 .

Fin relación con la pena de muerte, que fue tratada en diversas formus en las constituciones anteriores, la Constitución de 1979 dispone que "No hay pena de muerte, sino por traición a la Patria en caso de guerri exterior" (articulo 235): $Y$ cosno la Convención Americana de Derechos Humanos de la que el Perí es parte, prohibe extender la pena de muerte a delitus a los cuales no se aplique actualmenste (artículo 4 , inciso 2), resulca que el articulo $235 \mathrm{no}$ puede modificanse pana ampliar is aplica: ción de la muerte, pues ello exigiria la previa denuncia de la Convención Americanta de Derechos Humanos; y esto iria en contradicción con los fundarnentos de la Constitución de 1979 gue otorgan la más alta consideración a los derechos humanos y garantizan su protección no solo nacional, sino también dentro del sistema regional interamericano, asi como dentro del sistema universal de Naciones Unidas.

Una importante innovación de la Constitución de 1979 se refiere al idicma: "El castellano es el idioms oficial de la República. También son de uso oficial el quechua y el aimara en las zonas y la forma que la key establece. Las demás lenguas aborigenes integran asimismo el patrimonio cultural de la nación" (articula 83). Dispone también la Constitución que "El Estar. do promueve el estudio y conocimiento de las lenguas aborigenes".

Garantiza el derecho de las comunidades quechua, aimara y demás comunich. des nativas a recibir educación primatia tambiên en su propio idioma o lengua" (articulo 35). Sin embargo, la ley sobre el uso oficial del quechua y aimara aûn no ha sido dictada $y$ la educación primaria en quectua, aimara y lenguas aborigenes no ha sido establecida. El jdioma que utiliza la administración püblica, el Congreso, el Poder Judicial y demás órganos del fistado, ex únicamente el castellano. La educación se imparte también en casteltano. Es impostergable dar cumplimiento a las previsiones de los artículos 35 y 83 de la Constitución, poniendo en vigencia el derecho cultural de las comunidades quechua, amara $y$ aborigenes, a recibir educación $y$ a utilizar su propio idioma.

Otro aspecto de la Constitución de 1979 que exige particular atención es el relativo a los estados de excepción. El artículo 231 autoriza al Eecutiwo a declarar el "Estado de enengencia" por un plazo de 60 dias promogables, "en caso de perturbación de la paz o del onden interno, de catístrofe o de graves circunstancias que afecten la vida de la nación" pudiendo suspender las garantias sobre la libertad $\gamma$ seguridad per: 
sonales, 1 inviolabilidad del domicilio, la libertad de reunión y de tránsito en el territorio". Puede también el Ejecutivo declanar "Estado de sitio" por un plazo de 45 días, prorrogables con autorización del Congreso, "en caso de invasión, guerra exterior o guerra civil o peligro inminente de que se produzcan" debiendo especificarse "las gamantias personales que continúan en vigor". Si bien el "Estado de sitio" al que se refiere el artículo 231 de la Constinucion no ha sido nunca decretado, debe tenerse presente que dertas garantias personales no poeden ser suspendidas en ningún caso. Asi, el articulo 4, inciso 2 del Pacto thternacional de Derechos Civiles y Políticos prohibe suspender las siguientes garantías y derechos: derecho a la vida; protibición de la detención por no poder cumplir obligaciones contractuales; principio de la legalidad (nullum crime sine lege) y retroactividad; derecho al reconocimiento de la personalidad juridica y libertad de pensamiento, de conciencia y de religion. $A$ su vez, el articulo 27 , inciso 2 de la Convenciôn Americana de Derechos Humanos, prohibe la suspensión de los siguientes derechos: derecho al reconocimiento de la personalidad jurídica, derecho a la vida, derecho a la integridad personal, prohibicion de la esclavitud y servichumbre, principio de legalidad y retrouctividad, libertad de conciencia y religión, prosección a la familia, derecho al nombre, derechos del niño, derecho a la macionalidad, derechoo políticos y las garantias jurisdiccionales indispersiables para la protección de estres derechos.

Consecuentemente, las garantias y derechos citados deben mantenerse vigentes en toda circunstancia. Aun en Estado de sitin.

Una diting consideracion: confoeme a la sexta de las disposiciones generales y transitorias: "Las disposiciones constitucio: nales que irrogan nuevos gastos e inversiones, se aplican progresivamente. La Ley Anual de Presupuesto contempla el cumplimiento gradual de esta disposición". A su vez el articulo 25 de la ley 23506 esta. blece que "No dan lugar a la acción de amparo los derechos a que se refiere la sexta de las disposiciones generales y transitorias de la Constitución". Esto significa que los derechos econóninicos, sociales y culturales, es decir, los derechos a la alimentación, al trabajo, a la educación, a un nivel de vida adecuado, no están debidamente cautelados y protegidos.

Pero la misma Constitución de 1979 establece que "son deberes primordiales del Estado defender la sobcrania nacional, garantizar la plena vigencia de los derechos humanos, promover el bienestar general basado en la justicia $y$ en el desarrollo integral y equilibeado del pais, y eliminar toxha forma de explotación del hombre por el hombre y del hombre por el Estado* (articulo B0), En cumplimiento de este dispositivo, el Estado debe adoptar las medidas necesarias para garantizar la plena vigencia de los derechos humancs; tanto de los derechos civiles y politicas, como de los derechos económicos, scciales y culnurales, promoviendo el bienestar general de todos las peruanos sobre bases de justicia. 